\title{
A Brief Study of Cupules of a Few Megalithic Sites in Jharkhand
}

\author{
Subhashis Das \\ Individual Researcher, Hazaribagh, India \\ Email: subdas.hzb@gmail.com
}

Received October 03, 2016; Revised October 20, 2016; Accepted October 20, 2016; Published October 22, 2016

\begin{abstract}
:
Cupules have been reported from most of the states in the country. Not much is known about them, profound study is relentlessly being carried out by scholars across the country to unravel the mystery of these enigmatic relics of our ancestors. Albeit abundant study of cupules on rock surfaces continues much effort is essential to untangle their obscurity on megaliths. Jharkhand has an abundance of cupmark sites in caves, rock shelters, and rock arts and even on prehistoric megalithic sites that lie strewn all over the state. The paper in question comprises a study of cupules on four megalithic sites in and around Hazaribagh district of the Jharkhand state that are his personal discoveries. No excavation of these sites has been undertaken neither any tool nor flake has been recovered from the sites that could establish the monuments' and the cupules' possible age. The paper is not only a study of cupmarks but basing on certain belief systems of the megalithic tribes of Jharkhand it also attempts to seek various possible causes that may have prompted people in hoary antiquity to create these inscrutable indentations. Furthermore the paper also delves into the author's study how cupule making having gone through a transition still continues in an unrelenting manner among the present day peasants; the surface only having changed.
\end{abstract}

Keywords: Cupules, Hazaribagh, tribals, Megalith, Daraki Chattan, Gurua, Napo, Raja Gosain.

\section{Introduction}

Cupules are hemispherical depressions carved by the archaic humankind on surfaces of vertical, slanting and horizontal stones at an unknown antiquity for reasons yet not properly comprehended. The term cupule for the indents was actually coined by the eminent archaeologist R.G. Bednarik.

Research has shown that cupules need not always be circular but they could even be oval or triangular in shape (Kumar and Krishna 2014). Cupules in India appear on rock arts, on walls and floors of ancient caves but never on ceilings (Kumar and Krishna 2014), in megalithic sites and sometimes even on solitary outcrops. Cupules today have been elevated to the status of rock art (Kumar 1998). Credit to the discovery of cupules in megalithic sites in India should be granted to Rivett-Carnac who in 1879 recounted the sighting of cupules in the stone circles of Junapani in Maharashtra. Reports of finds of cupules on megaliths thereafter till the present times have been surfacing from megaliths all over the country.

Two most eminent cupule sites in India are of the Auditorium cave of the Bhimbetka rock art site and that of the Daraki Chattan; both are in the state of Madhya Pradesh of Central India. The

(c) AesthetixMS 2016. This Open Access article is published under a Creative Commons Attribution Non-Commercial 4.0 International License (http://creativecommons.org/licenses/by-nc/4.o/), which permits non-commercial re-use, distribution, and reproduction in any medium, provided the original work is properly cited. For citation use the DOI. For commercial re-use, please contact editor@chitrolekha.com. 
Bhimbetka Auditorium cave's rock art has been dated to about 27000 BC (Bednarik 2001). The cupule boulder site of Bajanabhat 1 and 2 too may belong to the same age (Kumar 1998) (Kumar and Sharma 1995). The Daraki Chattan houses around 498 cupules and has been dated to the Acheulian or the following transitional phase (Kumar 1995, 1996) and has been held to be the oldest in the country.

Cupules in a megalithic site can be observed on horizontal, recumbent and slanted stones as these petroglyphs are an ineffaceable component of many megaliths across the world (Das 2009). Information of cupules on menhirs although are sparse yet they still pour in as the one from Hirapur in Maharastra (Pawar, Kanti 2013). Cupule making has ceased to be a prevalent tradition today and as the cupule making ancients have left behind no written documents for the posterity it is difficult to comprehend the causes behind these mystifying indents on rocks.

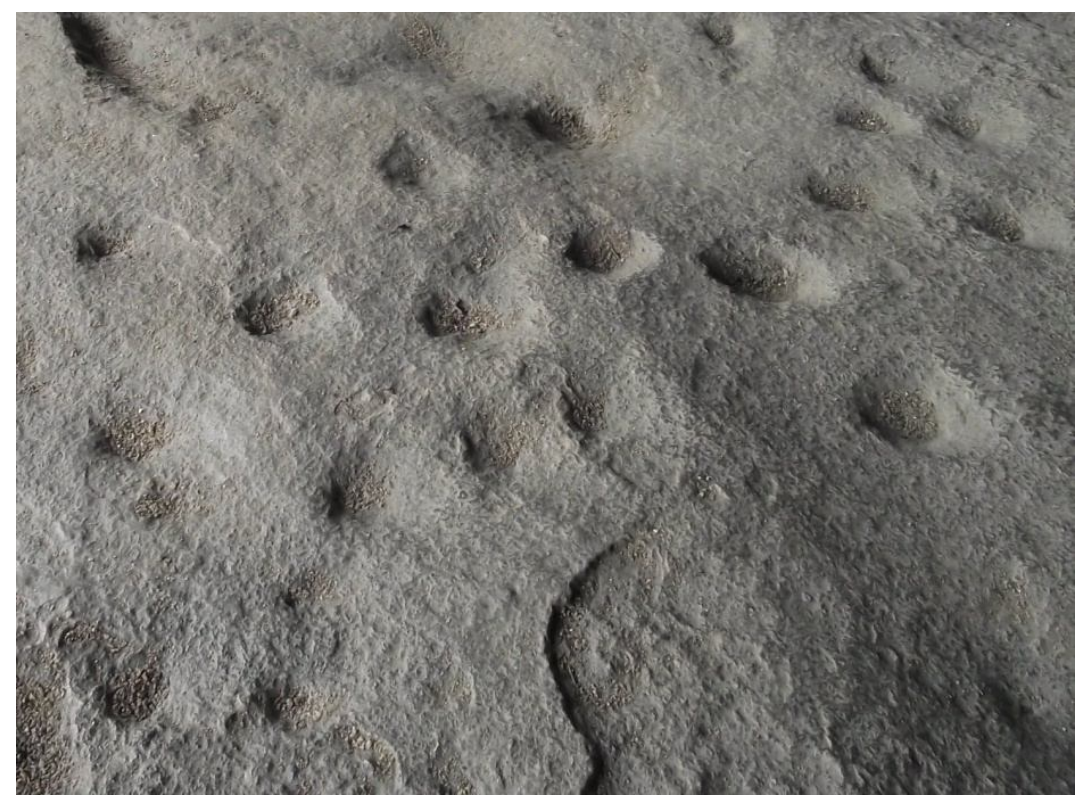

Figure 1. Circular and conical cupules inside the Maduadwar caves in Hazaribagh. Jharkhand

\section{Cupules of Hazaribagh}

Cupules in and around Hazaribagh can be seen in caves, rock shelters and arts and even in quite a few megalithic sites. One non-megalithic cupule site is the primitive Marwadwar cave near the Isko rock art site in Hazaribagh district where the cupmarks are on a horizontal stone. The site consists of about 40 of these depressions which are conspicuous and a few which have eroded. Many of these are circular and some are conical in appearance. (Fig 1)

That Jharkhand is a treasure house of megaliths is not known to many. Of the 24 districts, the state accommodates megaliths in most of them. Among the 30 tribes of the state, Munda, Oraon, Ho and Asur are four who are known to be megalithic today; in other words these tribes still erect megaliths on their dead since the Chalcolithic/Iron Ages. Which other tribes in the state were megalithic in the past and has presently deserted this custom, is not correctly known.

Jharkhand being a megalith-wealthy state has a large density of these ancient monuments. Many of these megaliths also house a good number of cupmarks; the scholarly world at large is oblivious of this cache. The author's exploration of the outback of Jharkhand has revealed many megaliths 
around Ranchi, Ramgarh and Hazaribagh that contain cupules among which the ones in Hazaribagh district and its adjoining areas bear their largest congregation. This however would not propose that megaliths in other districts are devoid of this rock art but implies that they have not been discovered, yet.

\section{Description}

Four types of cupules were observed in our survey of these primitive petroglyphs in the megaliths of Jharkhand. Firstly, the randomly engraved ones, secondly; the type comprising of two or three cupules interlocked with one another with slim channels. The third type of cupules was noticed to have been arranged in single linear mode. Such cupules were found having either North-South or East-West orientations or were also found to have been made without any such bearings. The final category was the extension of the third type having two parallel rows of these linear arranged cupules with 6/8/10 depressions in each placed adjacent to one another with or without any specific orientation. These depressions are not taken to be real cupules as village children have been seen incising these two lined cupmarks on flat rocks to play games of pebbles in them.

\section{Basantpur}

Basantpur is a village situated a few kms away from the eminent Tata group's TISCO coalmines of Ghatotand. The village though initially was in the Hazaribagh district is now in the district of Ramgarh.

Basantpur is a poorer version of the reputed megalithic complex of Punkri Burwadih near Hazaribagh. The finds of columned menhirs and amlakas in the site testifies the Hinduisation of this non-Aryan tribal megalithic site. The site is vandalsied today with menhirs, pillars, amlakas and stone cuboids lying scattered everywhere as if the monument was demolished with intention. The function of so many cuboids that lie strewn all over is not known but they could be the remnant of an ancient stone temple.

The cupules of this megalithic site are on the upper surface of a cuboid stone squeezed in between an overgrown tree (Fig 2). The cupules can be seen to have been chiseled at random on the surface of a single cuboid stone without any order. Many of these dents are levelled due to erosion making their counting difficult but it seems there could be around 50 of them. Wearing away of the cupules made measuring indeed a difficult exercise yet a few larger ones were found to be of diameters varying

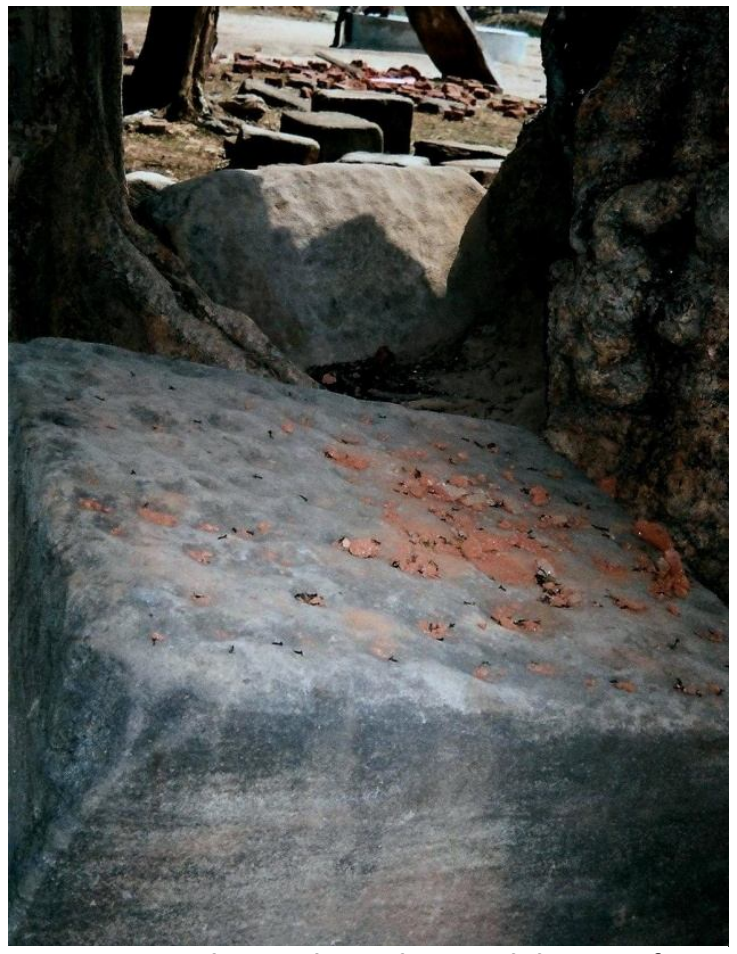

Figure 2. The cupules in the megalithic site of Basantpur. between 6 and $9 \mathrm{cms}$ and the smaller ones ranging from 3 to $5 \mathrm{cms}$. Their depths varied between $0.7 \mathrm{cms}$ and $1.5 \mathrm{cms}$. 
Rims of urns and pitchers peeping out of the soil around the megaliths confirmed that the bone burying satbharwaan ceremony was possibly prevalent till even a few years ago.

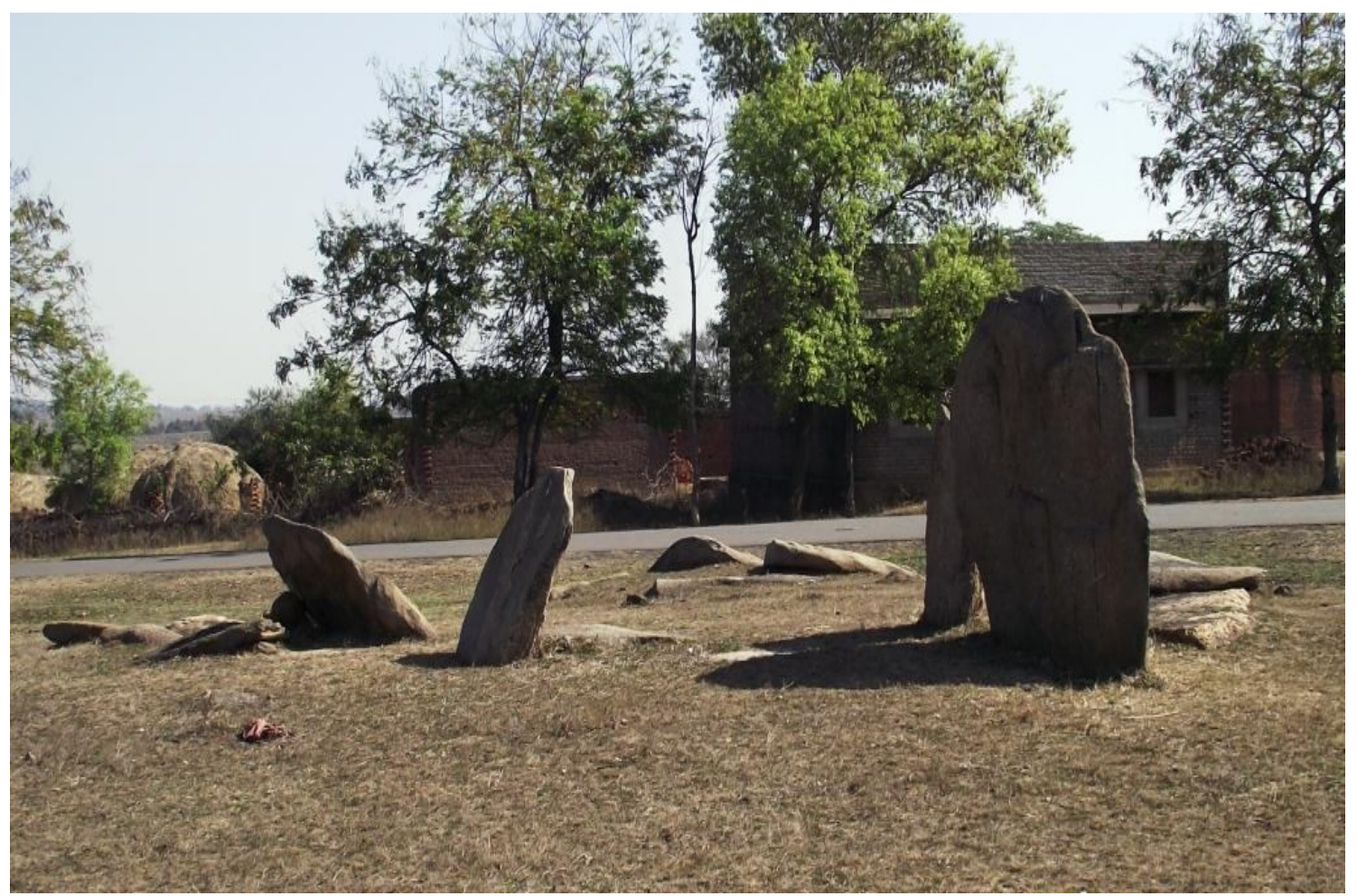

Figure 3. The Napo megalithic site.

\section{Napo: (Fig 3)}

When Napo was discovered it was in the Hazaribagh district which today has been acquired by Ramgarh district. This very ancient and alluring megalith lies about $40 \mathrm{kms}$ South of Hazaribagh town. The cupules in the site (Fig 4) are engraved at random without any order on two stones sited adjacent to one another of which one is inclined and the other lies flat on the earth. The cupule stones are placed in the North West of West periphery of a raised stone circle within the ancient megalithic complex which also houses two menhirs. The concentration of the cupules is more on the upper and the middle part of the inclined stone having approximate length and

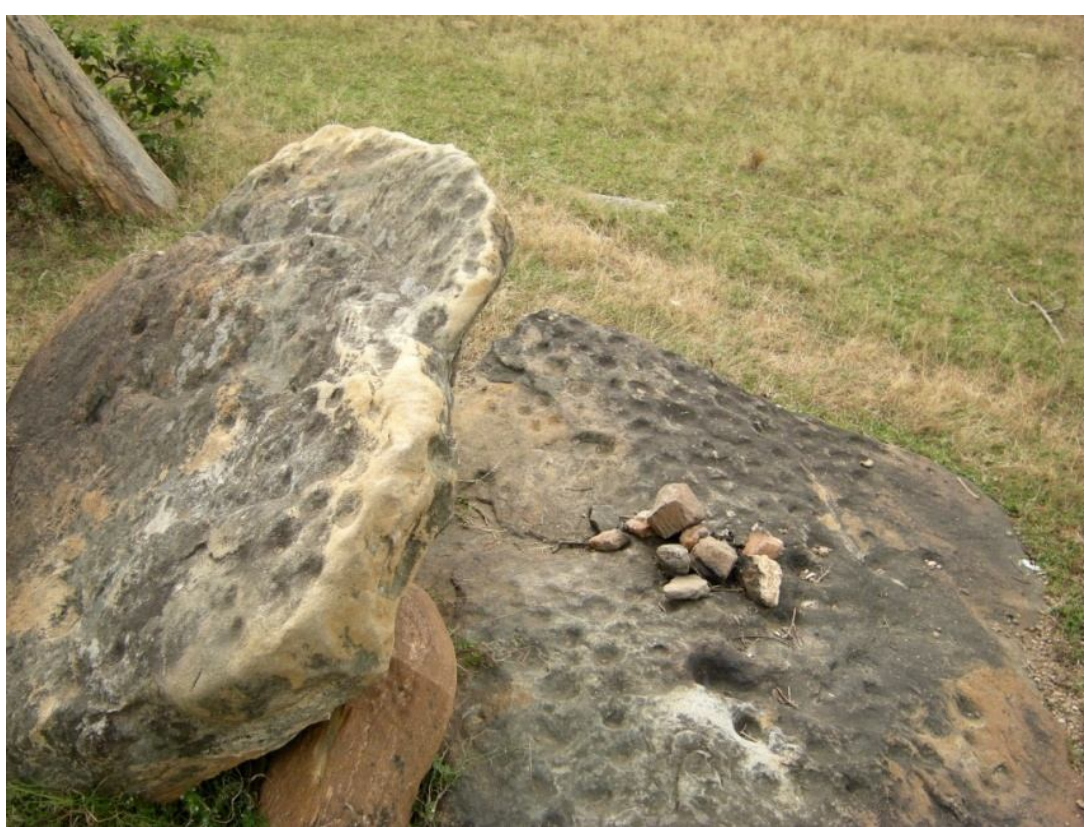

Figure 4. The cupules in two stones of the megalithic site of Napo. 
breadth of 1.22 and 0.91 meters respectively.

Few of the cupules were noticed even on the stone's girth but the lower part seemed devoid of them. Although most of the cavities have eroded today yet their diameters vaguely seem to range between 0.75 and $3 \mathrm{cms}$. The slanting stone may roughly comprise about 50 cupules. The resting stone approximately measures to about 1.32 and 1.15 meters in its respective length and breadth. The cupules on the recumbent stone are of varied dimensions. The largest ones have diameters ranging between 6 and $7 \mathrm{cms}$ with depths of around $5 \mathrm{~cm}$. The smaller ones vary from 3 to $5 \mathrm{cms}$ having depths between 1 and $2 \mathrm{cms}$.

The nearby village has a predominantly Hindu population with a fair amount of Muslims. Although most of the villagers are ignorant about the megaliths believing them to be naturally "grown" rocks, few however rightly believed that these were tribal burials of the olden days. The cupules in the site are an unknown entity for them. No tribals live in the Napo village but some do in the neighbouring ones. They when contacted affirmed that the site was raised by their ancestors at some hoary time but expressed their ignorance toward the cupules on the two stones.

One elderly person disclosed to us that his grandfather had shared with him that the stones were actually men of a marriage party who were petrified due to a reason which he now has regretfully forgotten; a story popular for megaliths all over the country and even beyond.

\section{Gurua}

The megalithic site of Gurua lies about $5 \mathrm{kms}$ to the south of South-East of Hazaribagh town and is located near a sacred grove. (Fig 5) Gurua originally discovered by Abhishek Mishra was once a very beautiful megalithic site. There are two medium sized menhirs of which the largest one stands about $1.424 \mathrm{~m}$ tall facing the Zulzul or the Seotagarha Pahadi at $120^{\circ}$ SE of $E$ the direction of Winter Solstice sunrise in this latitude. Two recumbent stones that serve as centrestones or burial covers under which the cinerary pots are buried bear the cupules. There are about eight large grooves whose diameters range between 10 and ' $12 \mathrm{cms}$ and their depths being rather shallow vary between 2 and $3 \mathrm{cms}$. The positioning of the cupules is more or less in North-South orientation in tandem with the megalith.

Today like many other megalithic sites of the state, Gurua too stands horribly ruined. A water trough has been built on the cupule stone by a villager who has constructed a hut on the megalithic site completely wrapping up the primitive cupmarks permanently.

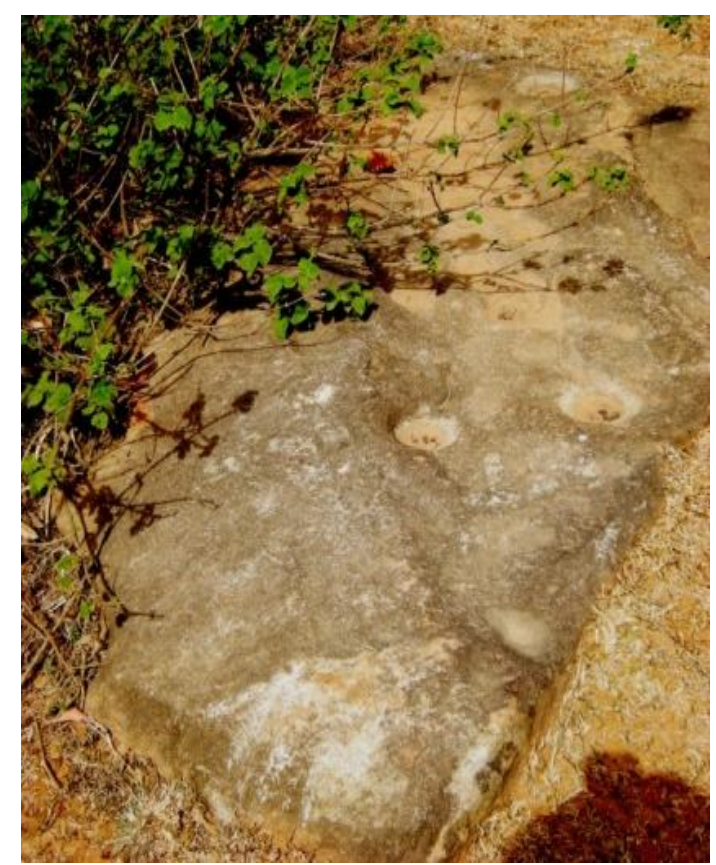

Figure 5. The cupules within the megalithic site of Gurua are on two recumbent stones which probably are also the covers of a burial of the site. Image shows one of such stones.

\section{Local Fables:}

The locals do not by any likelihood relate to the megaliths although many of them correctly conveyed to the author that they actually were burial stones of the tribals of ancient times who 
once inhabited the region. They could not however enlighten us on the cupules as most of them believed them to be natural creations.

\section{Raja Gosain}

The Raja Gosain megalithic cupule (Fig 6) site is about a 6 kms east of Hazaribagh town and is nestled behind the Silwar and the Jagannath hills. Raja Gosain, a revered local deity of the Silwar Village in actuality is an ancient menhir standing about $1.905 \mathrm{~m}$ tall and is oriented between 200 deg SW of S and 30 deg NE of N. A large tree that has grown adhering to the stone's side has surely disturbed its alignment; chances are that it was once may have had a North-South orientation at $0^{\circ}$ and $180^{\circ}$ respectively. The megalith along with the tree

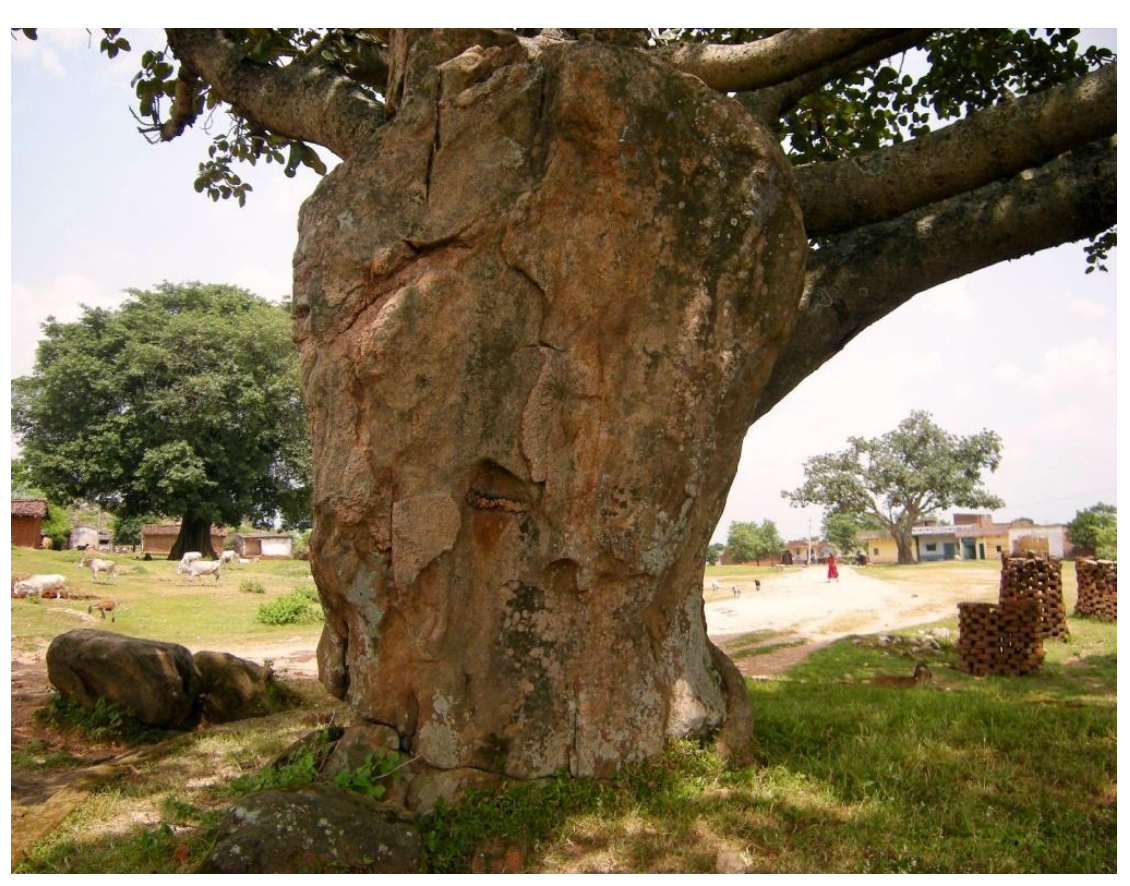

Figure 6. The Raja Gosaiwn menhir. The rocks around this sacred megalith houses the cupules.

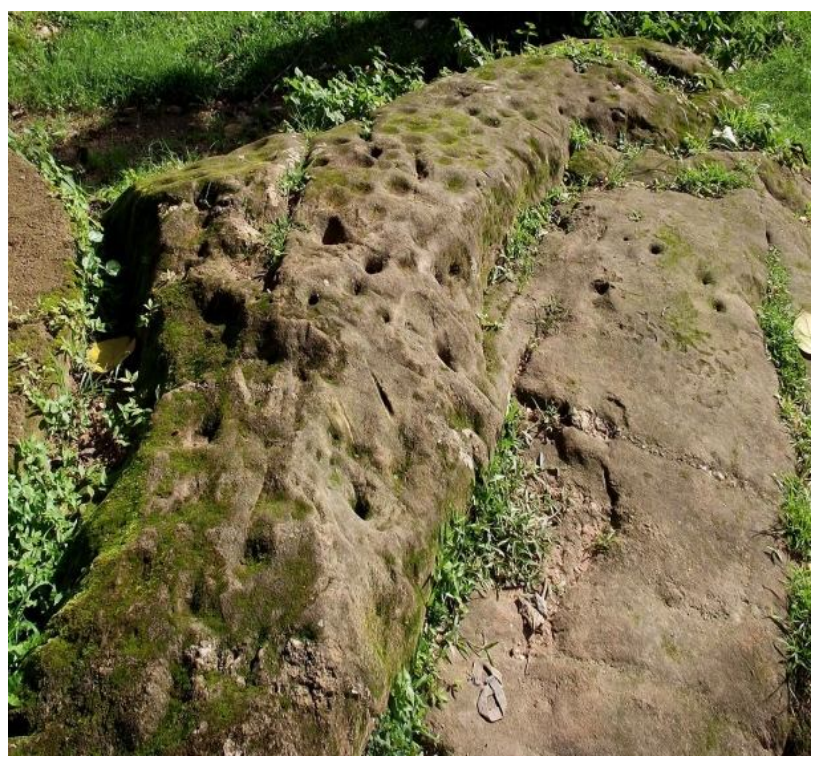

Figure 7. Rocks A \& B comprise 80 cupules approximately. has received a bricked platform today.

The outcrops that circumscribe the northern and the eastern fringes of the ancient megalith is home to quite a large number of cupules; such innumerable are the cupmarks on the stones in the site that it can easily claim to be the largest cupule site yet discovered in Jharkhand. One elongated and slender rock hereafter labelled Rock A (Fig 7) lies stretched to about 3.048 meters at the eastern side of the Raja Gosaiwn menhir in a NW/SE orientation which curves towards the SE edge. Cupules of varied sizes can be observed on its surface. The diameters of the smaller cupmarks were found to be between 8 and $4 \mathrm{cms}$ with varying depths between 1 and $4 \mathrm{cms}$ respectively. Counting the exact number of the petroglyphs was not feasible as many of them exposed to the sun, wind and the rain were nearly eroded. Yet a vague count tentatively showed about 80 cupules on it. The petroglyphs were seen to be in a near NW/SE alignment in accord to the shape of the boulder. 
A narrow boulder hereafter termed Rock B lies parallel to Rock A is home to five cupules (Fig 7). Contiguous and parallel to Rocks A and B is the Rock C (Fig 8 and 9) which stretches to an approximate length of about $\mathbf{2 . 1 3 3}$ meters. This is a raised boulder with a swell in the middle and is profusely cupmarked. The sizes of the cupules on Rock C corresponding to Rock A are not uniform with the diameters of the largest depressions varying between 10 and $11 \mathrm{cms}$ housing common depth of $4 \mathrm{~cm}$. The smaller depressions were found to range between 4 and $6 \mathrm{cms}$ and depths fluctuating between 1 and $2 \mathrm{cms}$. Few cupmarks with conduits are present here too; this design is apparent among two and three cupule sets; like the cupmarks themselves the meaning of this pattern still eludes us. The orders of the glyphs are not fixed but some did reveal an EastWest orientation.

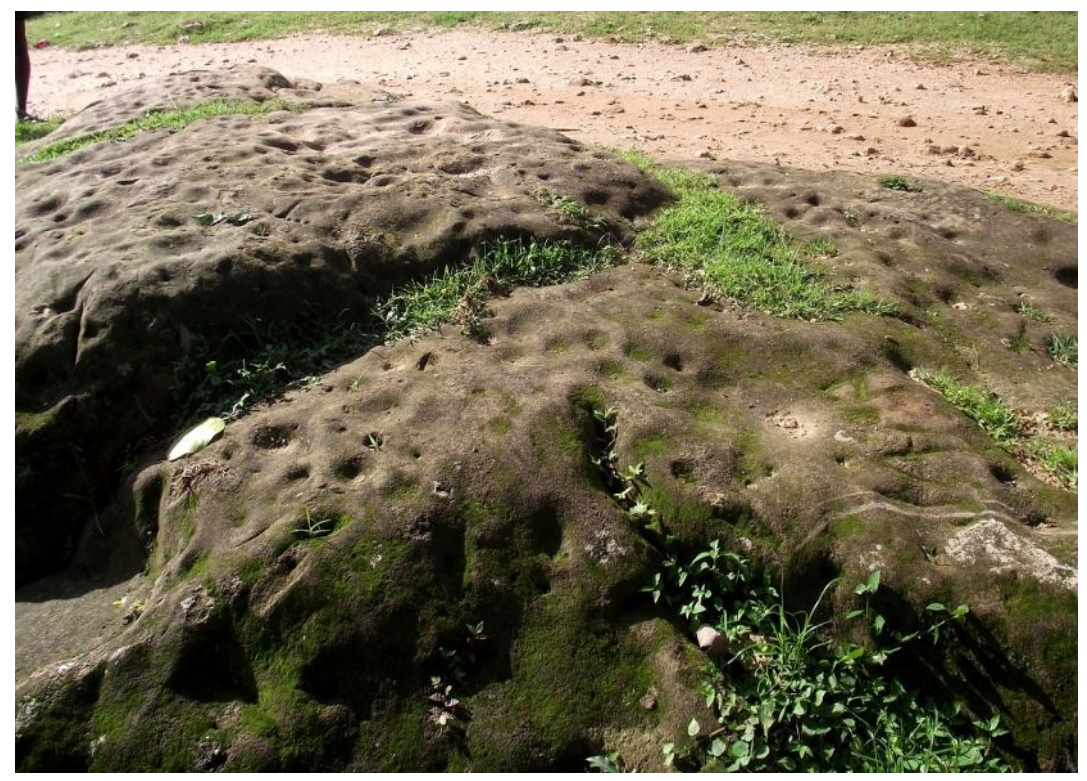

Figure 8.

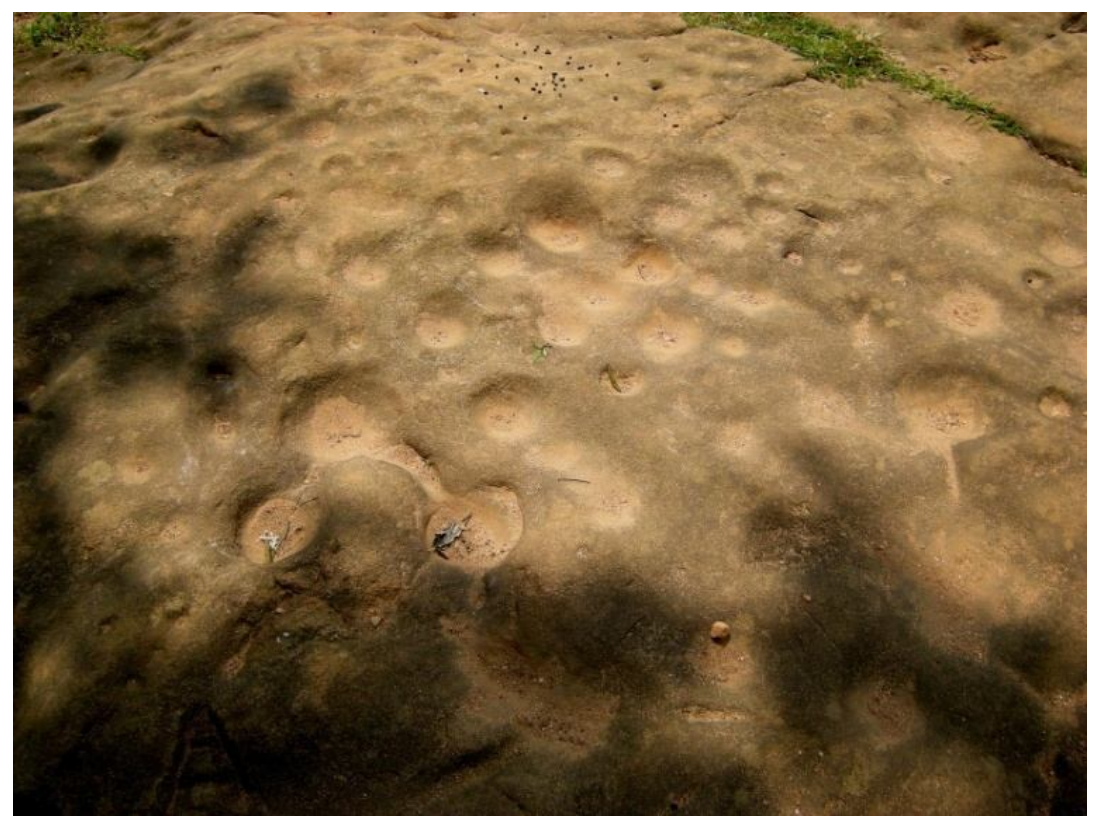

Figure 9. Both the photographs show Rock C that contains more than $\mathbf{3 0 0}$ cupules among which at least three are connected with conduits. 
On the Northern side of the Raja Gosaiwn menhir a few more rocks can be clearly detected. These have been dubbed as Rock D, E, F, G and $\mathrm{H}$ respectively which can be seen to be abundantly cupmarked. Rocks D (Fig 10) has cupmarks laid down in two parallel lines. One column comprise 10 circles while the other 8 . They were seen to be placed in a tentative East-West direction. The petroglyphs revealed erosion but having diameters of approximately 10 and $11 \mathrm{~cm}$. One cupmark was found to have been engraved in between the first two depressions of the west flank of the two rows. On the eastern part concealed below a thick shrub we spotted a few large eroded cupules.

Rock E (Fig 10) is a parallel stone which consist of a two-rowed worn out cupule set

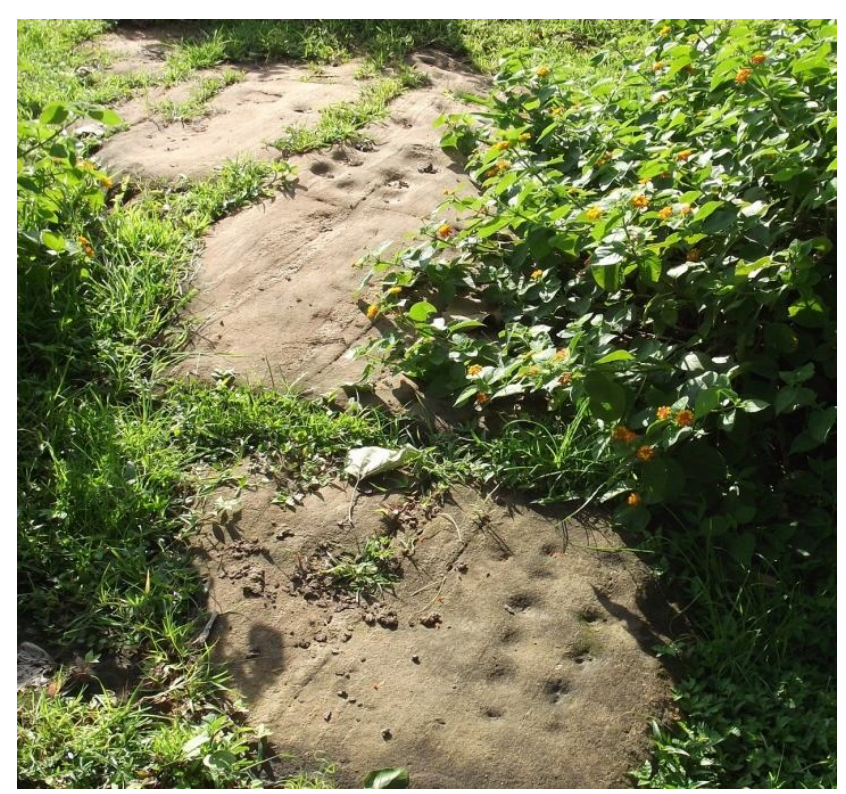

Fig 10. Rocks D \& E are adjacently placed rocks on which are the two lined cupules. with 6 cupmarks in each. As discussed in the above Bednarik has opposed to the idea of such two rowed cupmarks as being true cupules. These depressions are still made by village children as game boards in which they play games of pebbles. Rock $\mathrm{F}$ is the neighbouring stone of $\mathrm{D}$ and is on its western edge and has a near east-west orientation. Erosion has made determining the exact number of cupules on this stone difficult but a rough count could place the depressions to be around 12 to 14 . Rock $G$ has a unique petroglyph resembling a 6 and 9 done in the middle. A cupule has been carved in exactly at its centre.

Rock $\mathrm{H}$ lies more towards the road which too possesses a few cupules faded with wearing. At the western flank of $\mathrm{F}$ is a prominent cupmark. Hindu women are known to pour milk into this cupule.

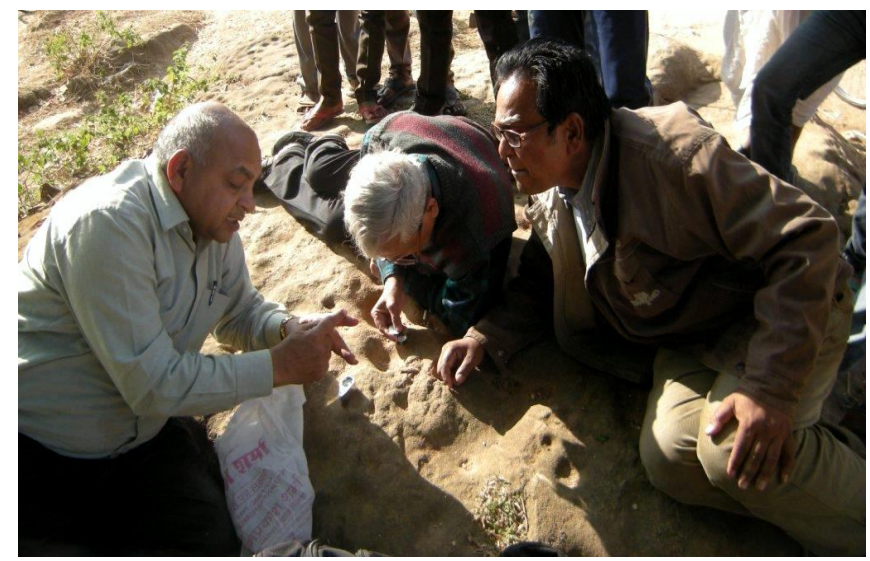

Figure 11. Dr.Giriaj Kumar the cupule expert and the author discusses the cupmarks on Rock $C$.

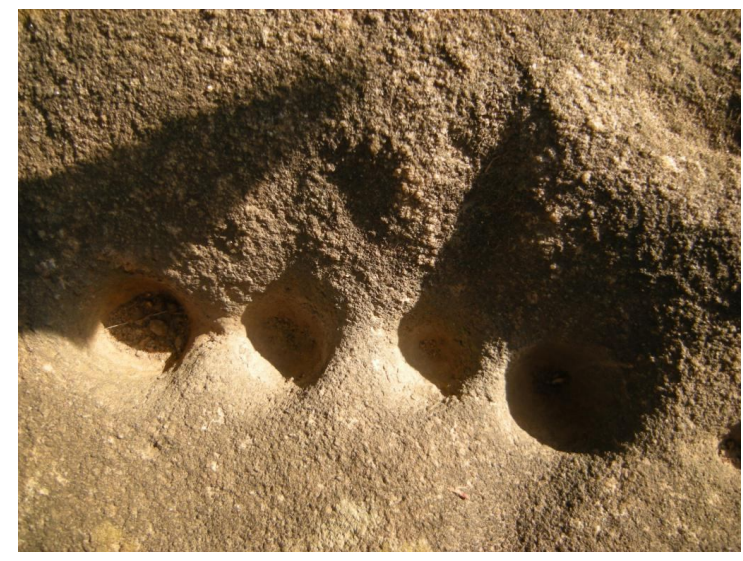

Figure 12. One of the few cupules on Rock $C$ which Dr.Giriraj Kumar opines to belong to the Iron Age.

Dr. Giriraj Kumar, the cupule expert of India during his examination of the cupules of the site showed his amazement (Fig 11). He also found a few cupules on Rock $C$ about which he expressed the possibility to have been made with iron tools during the Iron Age (Fig 12). 


\section{Comment}

The Raja Gosain is indeed the largest cupule site discovered so far in the Jharkhand state of east India. The presence of so many cupmarks on the stones suggests that this must have been a very significant sacred site for the primitives and the glory of this temple must have spread far and wide. The tall standing menhir was perhaps erected by the cupule makers or by the later day tribes to pinpoint the position of the temple to the primitive pilgrims from a distance. In times to come when cupule making became defunct, the menhir must have served as a village boundary marker and was revered by crowning it with the title Raja Gosain.

\section{Local Fable}

When enquired what exactly these circular depressions were, the villagers notified us that they were self evolved and a few others cited that these were created by the village children. A few however mentioned to us that these dents were called bhurkis and even satbharwaan. Bhurki is the colloquial tongue referring to holes, depressions or vents. The mention of the term satbharwaan by a section of the villagers was major as it is the 'bone burying ceremony' that although dying is still prevalent among the peasants and the non tribal dalit communities since much antiquity. The villagers however expressed their helplessness when inquired the reason behind the megalith being labelled Raja Gosain. The menhir bearing vermillion marks revealed to us that it was frequently worshipped.

\section{Discussion}

\section{The Cupule Problem in Jharkhand}

As no modern day megalith-making tribe makes cupules on megaliths or on independent stones today it is difficult to which tribe the cupules or the prehistoric megaliths could be ascribed. One can trace megaliths on the migratory track narrated in their journey tradition but surprisingly the monuments are devoid of cupules. It is as if the cupmarks have suddenly emerged in Hazaribagh. Which path the cupule folks may have adopted during prehistory to enter Hazaribagh is unclear. The migratory lores of the megalithic Mundas and the Oraons distinctly reveal a southwards movement i.e. towards Ranchi and Ramgarh from Hazaribagh. Several megaliths in and around Ranchi comprises cupmarks. It seems that the megalithic Kolarian tribes may have moved towards South Jharkhand with their cupule technology but wherefrom they may have entered the Hazaribagh region is still imprecise. A serious study of the cupules in the megalithic sites of Jharkhand and Hazaribagh is indeed required to solve both the megalith and the cupule problems in the state.

It is also strange that not all stones in megalithic complexes are cupmarked, rather only a few or even a single stone in the site would contain them. Megaliths in Jharkhand are believed to belong to $3^{\text {rd }}$ and $4^{\text {th }}$ cent BC. No proper excavation has been conducted of the sites in question hence no scientific data is available for these significant tribal monuments. Potshards and iron slags that lie scattered around the megaliths could be of much later days and may not even involve the cupules or the megaliths. However there are occasional reports of yields of artifacts resulting from tilling of the nearby fields by the plough which may or may not be connected with the megalithic cupules. 


\section{Possible Purposes}

Although it is difficult to explain the function of these cupules during the prehistoric times (Bednarik 2001) let us yet make an attempt to peek into the possible reasons that may have prompted our ancestors to create these enigmatic depressions on stones.

The Silwar villagers' associating the Raja Gosain cupules with the 'satbharwaan' rite opens a new chapter for cupules. The much ancient satbharwaan ritual is a bone burying ceremony which is still prevalent among the rural peasants since much ancient time. The rite demands placing of the cremated bones of the deceased into a small pitcher and thereafter burying it ritualistically beside a menhir or even immersing them into rivers. Therefore going by the name of satbharwaan for the cupules, a hypothesis could be drawn that these were perhaps created as commemoration posterior to the funerary ritual of a dead person of the community.

Circles and ovals in all civilizations have always been held as the symbol of the female vulva and subsequently as the representation of the Great Goddess; an appendage of the now defunct fertility cult that once had carpetted the prehistoric world (Das 2014). That cupmarks were once associated with female significance and were also held as symbols of the Mother Goddess is now widely accepted (Meaden 1999). The custom of pouring milk on certain cupules in a stone may also be indicating to the belief of holding these circular depressions as the female yoni representative of the ubiquitous Mother Goddess (Das 2008). Such an act could either be the continuation of a very old convention initiated by the populace who may have created the cupmarks millennias ago or be a later adjoined ritual to the more ancient cupules by a different community who may have entered the locality subsequent to the exodus of the cupule making multitude from the region.

The proto-austroloid Kolarian tribals in Jharkhand who still erect megaliths on their dead regard circular engravings on any surface as 'Uri'. Similarly the dreadful poxes on humans which too have circular shapes are also called 'Uri' by them. In non-technological societies of the tribals and of the rural peasants poxes are considered to be the upshot of the wrath of the Goddesses or the Devi Ma hence are deemed as the Goddess themselves. Therefore cupules or uris might also be the earlier symbols of such outbreaks of chicken and small poxes which must have been very common in ancient times. Engraving the

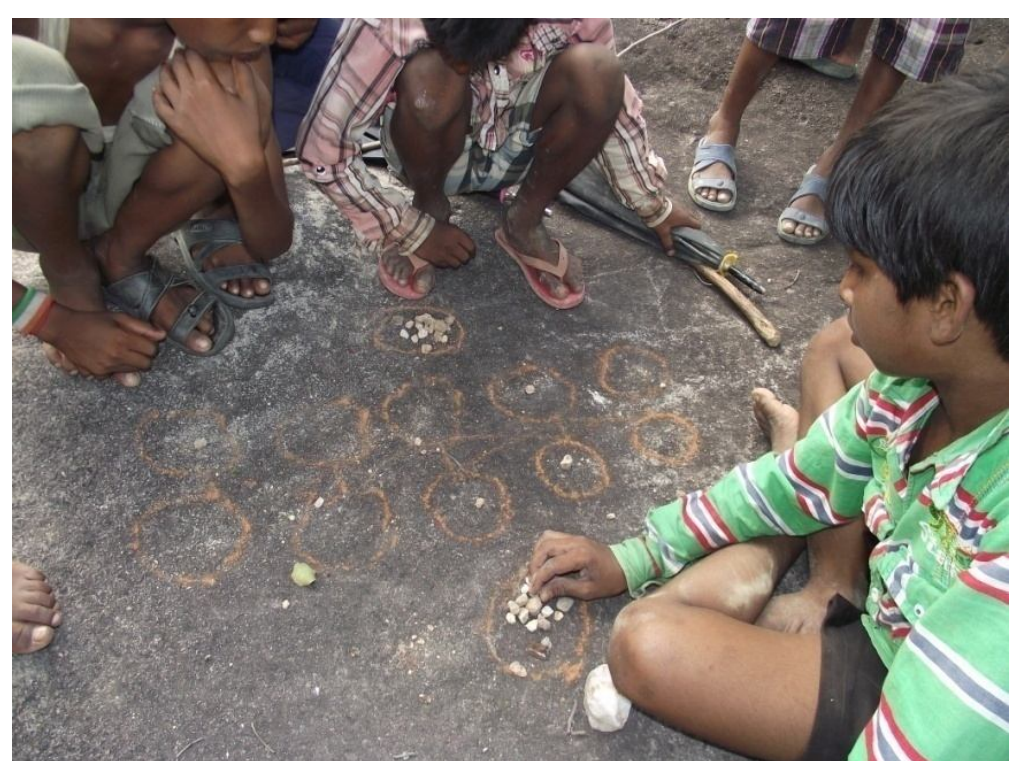

Fig 13. Photograph shows village children having drawn a two rowed 10 cupule set with brick plays a game of pebbles in them. cupules on stone surfaces was perhaps in a way to honour the Great Goddess to pacify her wrath. 
Several scholars have also surmised that these cupules oriented towards the cardinal points could also have astronomical connotations (Pawar 2013). Village children play with pebbles in the two-

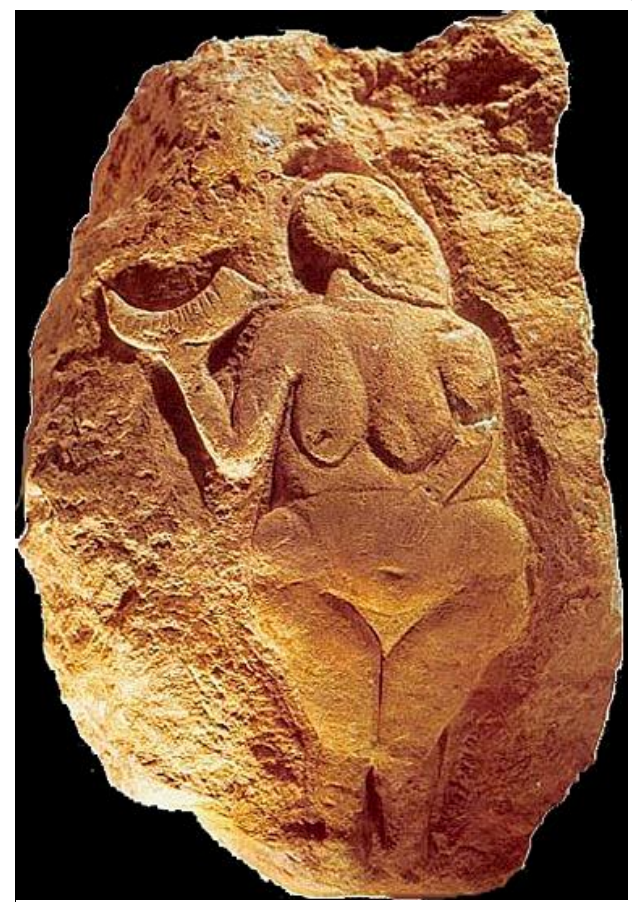

Figure 14. The Venus of Laussel in France holds a bison horn with 13 notches.

Source: elsomnideladeessaterra.blogspot.com rowed cupmark sets on horizontal stones comprising of 5 , 6 or even 8 engravings in each making a total of 10,12 or 16 depressions (Fig 13). Chances are that these types of cupmarks may have come down from more primitive times when such cavities were probably used as lunar calendars based on the moon's waxing of 13 days and the full-moon phase of 3 days making a sum of 16 days representative of the same number of cavities.

The nude figurine of the Venus of Laussel found in the Paleolithic cave of Southern France holds a bison horn which many believe to be the crescent moon on her right hand which is inscribed with 13 lines (Fig 14). The 13 incised lines may correspond to a 13 month lunar calendar or to half a lunation period from New Moon to Full Moon or vice versa (Rao 2005) or perhaps denote the number of menstrual cycles in one year. The crescent head gear worn by 'proto Shiva' on the Mohenjodaro seal too has markings which too may be notations of a lunar calendar (Rao 2005). A 13 indentation set was discovered by the author on a rock in a very ancient megalithic site near Hazaribagh which could have served a similar astronomical purpose (Fig 15).

The count in the 10,12, 15 or 16 cavities of the assumed lunar calendar was perhaps made by the placing of pebbles inside the cupules. When astronomy and cupules disappeared from megaliths these particular type did not fall into disuse but were adopted as game boards with pebbles which were once used for counting days of the moon (Das 2014).

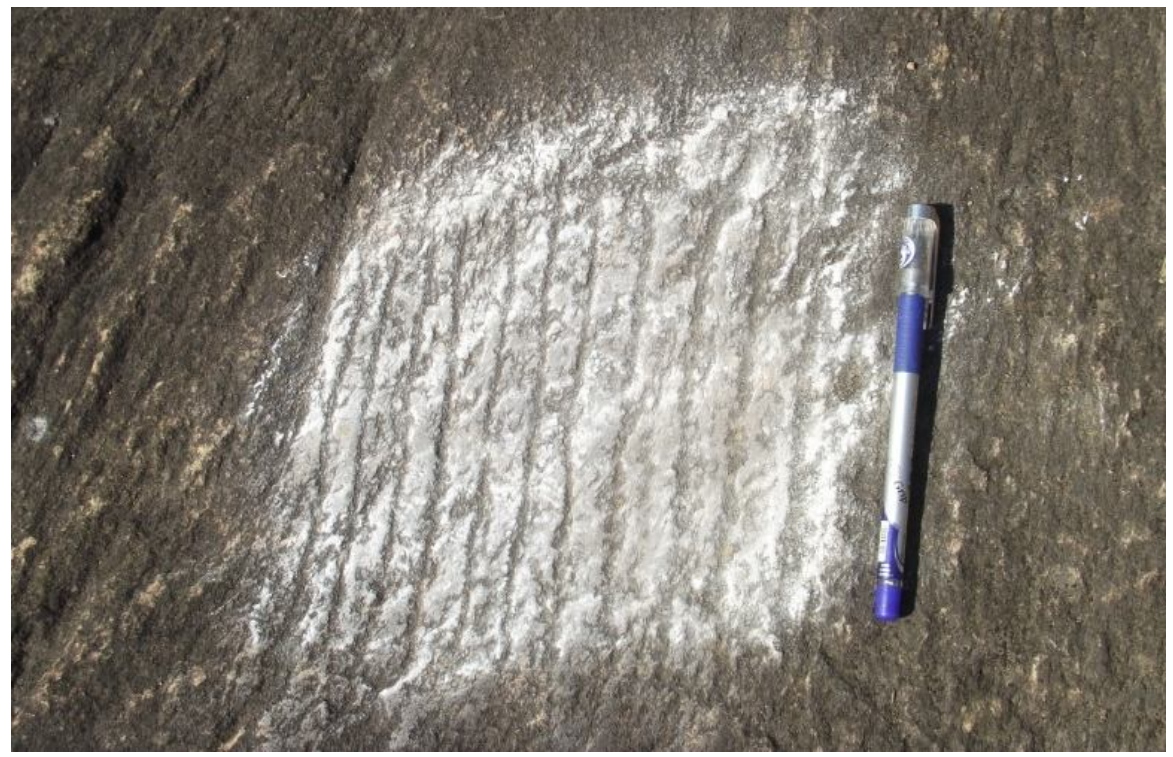

Fig 15. A set of 13 parallel notches having an east-west orientation was discovered by the author on a rock outside Hazaribagh . 


\section{Present Tradition of Cupules}

Cupule making although is a forgotten custom today but is still prevalent in a different form among several non tribal peasant communities. The day subsequent to Diwali, festivals such as Sohrai and Godhan etc are held. The festivals on this day are designated to domestic cattle in which cattle are bathed and their horns are anointed with mustard oil in the morning. Thereafter red circles replicating the archaic cupules are smudged all over their body surfaces with an earthen lamp or diya; which too is deemed as the symbol of the Mother Goddess (Meaden 1999) (Fig 16).

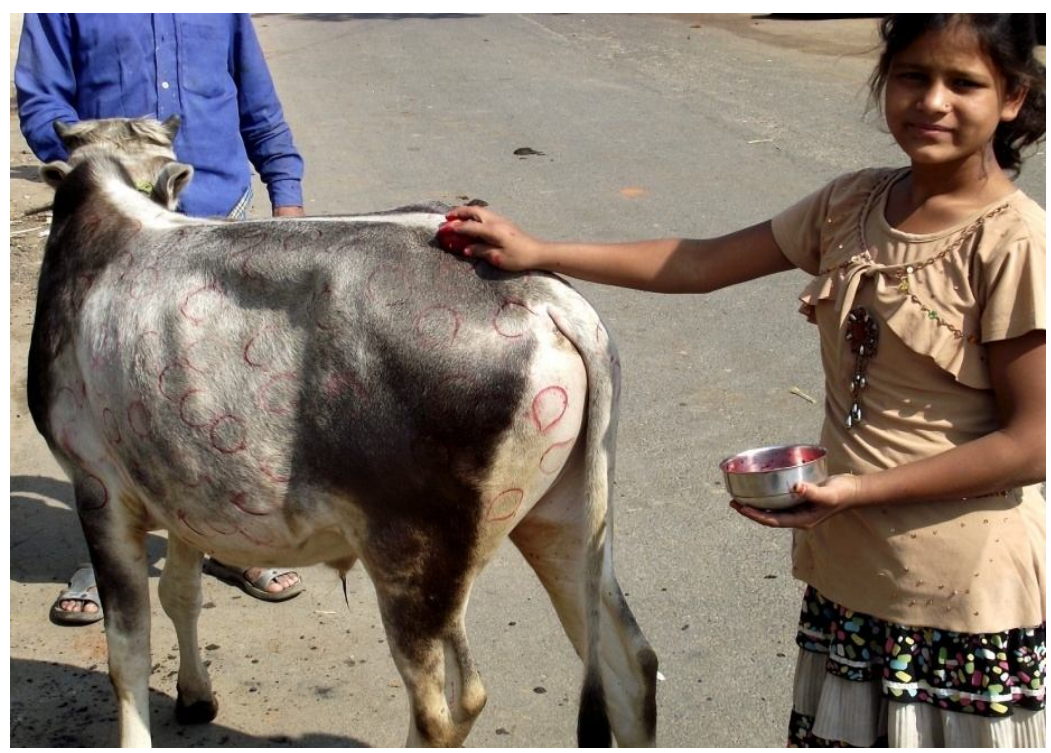

Figure 16. Little girl applying cupmarked designs with an earthen lamp (diya) on a cow during Govardhan Puja.

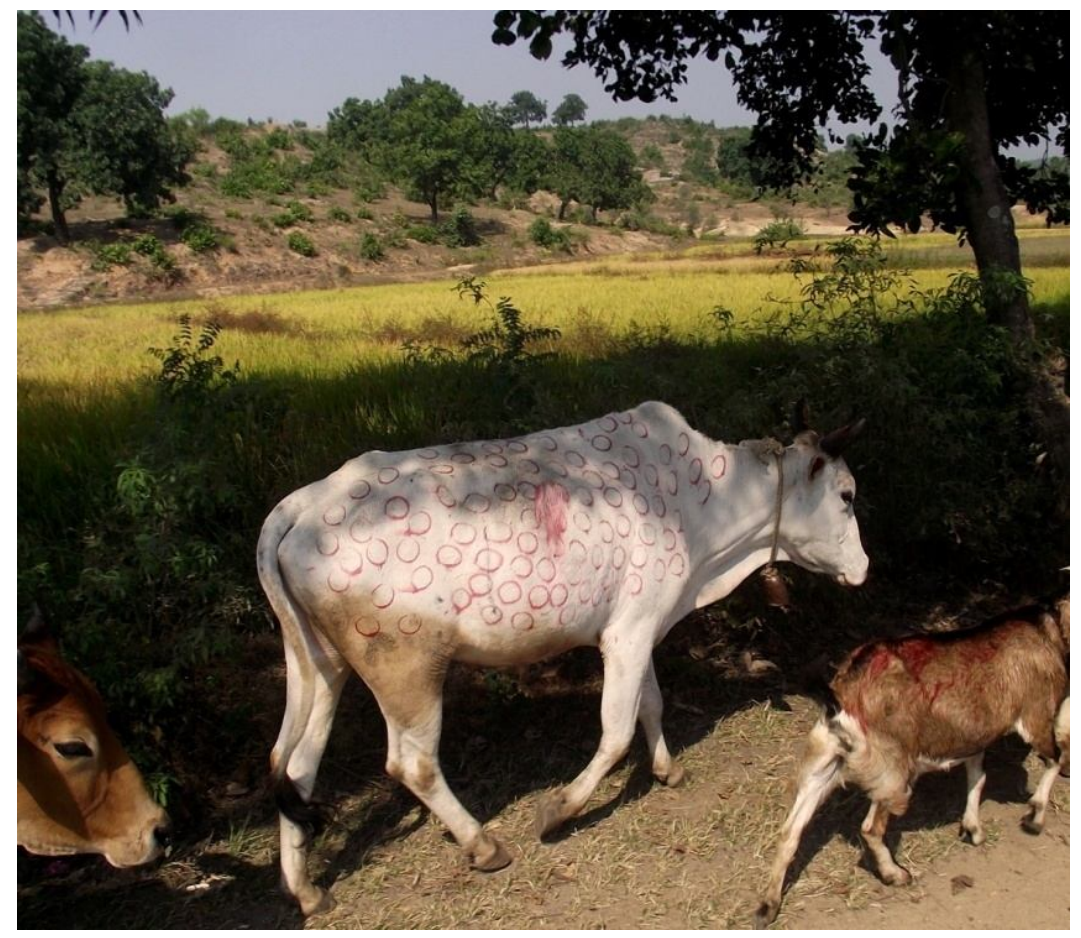

Figure 17. Cow flaunting cupule patterns on her body surface done during the Govardhan Puja. 
These red circular patterns on the cattle are indeed held as the representative of the Mother Goddess therefore are fecundity symbols whose application on the bodies of the cattle stock are believed to augment their fertility prowess. The circular blotches on the cattle (Fig 17) are indeed cupules that live among us serving more or less one of the same purposes as that of fertility symbols only the surface of the stone has paved the way for cattle.

\section{Conclusion}

From the above study this can be surmised that cupules perhaps functioned as commemoratives of the dead, as fertility symbols meant to augment the fertility of their women folk or of their domesticated animals and the two rowed cupule sets as lunar calendars which later transformed in to game-boards.

It cannot however be asserted with certainty that the cupules in the megalithic sites were the creations of the same megalith makers. Despite the misgivings it is well established that cupules in caves and rock shelters are of much earlier dates. Therefore a proper excavation of the site is either liable to push back the dates of Jharkhand megaliths and their cupules to farther antiquity or authenticate the megaliths' construction dates to the already held beliefs of their belonging to the Chaclolithic or the Iron Ages. The Raja Gosain cupule site indeed looks very old but also requires an excavation to substantiate its antiquity.

Furthermore the funerary, astronomical and the fertility practices of the megalithic tribes as that of the Mundas, Oraons, Asurs and the Hos of Jharkhand and the cupule like red smudge applications on the cattle by the peasants require more detailed studies as in these customs the solution to the cupule riddle surely lie hidden.

\section{References:}

Bednarik, R.G. 2001. Early Petroglyphs and their Global Context. Purakala: 11-12.

Das, Subhashis. 2008. Some Salient Features of the Surface Architecture of megaliths of Hazaribagh. Puratattva. Number 38: 181-185.

Das, Subhashis. 2009. Sacred Stones in Indian Civilization. Kaveri Books. New Delhi: 101-104 .

Das, Subhashis. 2014. Unknown Civilization of Prehistoric India. New Delhi: 64-65.

Kumar, G and Krishna, R. 2014.Understanding the technology of the Daraki Chattan cupules: The cupule replication project. Rock Art Research. Vol 31. No 2: 177-186.

Kumar, Giriraj. 1995. Daraki-Chattan: a Paleolithic cupule site in India. Purakala 6.

Kumar G. 1998. Morajhari: a unique cupule site in the Ajmer District, Rajasthan. Purakala $\quad 9: 61-64$.

Kumar, G. and Sharma, M. 1995. Petroglyph sites in Kalapahad and Ganesh Hill: documentation and observations. Purakala 6: 56-59.

Meaden, Terence. 1999. The Secrets of the Avebury Stones. Souvenir Press. London. 5.

Pawar, Kanti. 2013. The Excavation at Hirapur 2010-11: A Typological Variant in megalithic Cultures of India. www.megalithindia.in

Rao, N. Kameswara. 2005. Aspects of prehistoric astronomy in India. Bulletin of Astronomical Society of India 33: 501-504. 
Subhashis Das was the Principal of a High School but is better known as an individual researcher of megaliths of India, tribal civilizations and culture and tribal folklores. He has the distinction of discovering many unknown megaliths of the country. He has also discovered the astronomy of Punkri Burwadih megaliths and the much ancient Equinox sunrise viewing from the site. He has authored three books on his discovery and research on megaliths which are of course the first books on megaliths in the state of Jharkhand: In Quest of the Megalith, Sacred Stones in Indian Civilization, Unknown Civilization of Prehistoric India. He also writes in many national and international journals and his work has been featured in many documentaries and in many significant venues across the world. He has also been invited to speak on his research in many countries across the world. He also runs the only website on megaliths of India: www.megalithindia.in. 